\title{
Gambling disorder, increased mortality, suicidality, and associated comorbidity: A longitudinal nationwide register study
}

\author{
ANNA KARLSSON ${ }^{1,2}$ and ANDERS HÅKANSSON ${ }^{1,2 *}$ \\ ${ }^{1}$ Faculty of Medicine, Department of Clinical Sciences Lund, Psychiatry, Lund University, Lund, Sweden \\ ${ }^{2}$ Clinical Research Unit, Malmö Addiction Center, Region Skåne, Sweden
}

(Received: May 28, 2018; revised manuscript received: September 8, 2018; accepted: October 14, 2018)

\begin{abstract}
Background and aims: Gambling disorder (GD) appears to be an independent risk factor for suicide, and all-cause mortality has been sparsely studied in patients with GD. This study aims to explore mortality and suicide rates in individuals with GD compared to the general population as well as explore risk factors associated with all-cause mortality and suicide mortality. Methods: This is a nationwide register study on 2,099 individuals with a GD diagnosis in the Swedish inpatient and/or outpatient specialist health care system between the years of 2005-2016. Comorbid diagnoses from treatment episodes included in national registers were categorized into diagnostic groups according to the 10th revision of International Classification of Diseases, and prevalence rates (any occurrence during 2005-2016) were calculated for each diagnostic group. Multivariate Cox regression analyses on risk factors for death and suicide were performed, controlling for age, gender, and major categories of comorbidity. Standardized mortality ratios (SMRs) were calculated for men and women with regard to overall mortality and suicide compared to the general Swedish population. Results: The population consisted of 1,625 men and 474 women ranging from 18 to 83 years of age at first GD diagnosis (mean: 36.5 years). Sixty-seven individuals passed away, among whom 21 deaths were due to suicide. SMR calculations showed a 1.8-fold increase in mortality for individuals 20-74 years old with GD compared to the general population, and a 15 -fold increase in suicide mortality. All-cause mortality was predicted by higher age and any treatment episode for cardiovascular disease, whereas suicide death was predicted by depression. Discussion and conclusions: Mortality and suicide rates are significantly elevated among individuals with GD. Although common mental health comorbidities did not predict overall mortality, depression predicted suicide death. Findings call for attention to long-term risk of death in GD patients and interventions against comorbid health problems.
\end{abstract}

Keywords: gambling disorder, suicide, mortality, comorbidity, standardized mortality ratios, nationwide

\section{INTRODUCTION}

The prevalence of problem gambling [including both problem gambling and gambling disorder (GD)] has been estimated to somewhere between $0.12 \%$ and $5.8 \%$ (Calado \& Griffiths, 2016), and lifetime prevalence rates for GD have been estimated to around $0.5 \%$ (Kessler et al., 2008; Petry, Stinson, \& Grant, 2005).

An association has been found between problem gambling and completed suicide (Blaszczynski \& Farrell, 1998), which means that problematic gambling has been described to be relatively common prior to suicide (Wong, Cheung, Conner, Conwell, \& Yip, 2010), and authors have called for increased knowledge about the connection between gambling and suicide (Tse, Tang, \& Wong, 2014). However, several studies on gambling and suicidal behavior have been focused on non-fatal suicide attempts, or suicidal ideation, consistently showing high rates of suicidal ideation or suicide attempts in problem gamblers, in comparison to the general population (Hansen \& Rossow, 2008; Kausch, 2003; Komoto, 2014; Ledgerwood, Steinberg, Wu, \& Potenza, 2005; Moghaddam, Yoon, Dickerson, Kim, \&
Westermeyer, 2015; Ronzitti et al., 2017). Newman and Thompson (2007) demonstrated that GD was associated with elevated risks of attempting suicide, with an odds ratio of 3.43 (95\% CI: 1.37-8.60; Newman \& Thompson, 2007).

Given these alarming numbers, more knowledge is needed to identify individuals at risk. Currently, however, fewer than $10 \%$ are estimated to seek help for their GD (Braun, Ludwig, Sleczka, Buhringer, \& Kraus, 2014; Suurvali, Hodgins, Toneatto, \& Cunningham, 2008), making research on and prevention of suicide challenging.

For non-fatal suicidal behavior, several risk factors have been identified among individuals with GD, such as depression (Newman \& Thompson, 2007), cluster B personality disorders (Bischof et al., 2015), alcohol dependence (Newman \& Thompson, 2007), or a co-occurring attention-deficit and hyperactivity disorder (Retz, Ringling, Retz-Junginger, Vogelgesang, \& Rosler, 2016). In addition, studies have

* Corresponding author: Anders Håkansson; Clinical Research Unit, Malmö Addiction Center, Södra Förstadsgatan 35, plan 4, Malmö S-205 02, Region Skåne, Sweden; Phone: +46 7031356 77; Fax: +46 46149 853; E-mail: anders_c.hakansson@med.lu.se

This is an open-access article distributed under the terms of the Creative Commons Attribution-NonCommercial 4.0 International License, which permits unrestricted use, distribution, and reproduction in any medium for non-commercial purposes, provided the original author and source are credited, a link to the CC License is provided, and changes - if any - are indicated. 
concluded that while male gamblers are in majority, female gamblers may be at increased risk of attempting suicide (Bischof et al., 2015; Husky, Michel, Richard, Guignard, \& Beck, 2015; Komoto, 2014). While Newman and Thompson (2007) observed that the increased risk of attempting suicide for women was explained by their higher prevalence of depression (Newman \& Thompson, 2007), another study demonstrated that female gender was indeed a weak but independent risk factor for attempting suicide when controlling for depression (Bischof et al., 2015).

In addition, and compared to the extensive literature of mortality on substance-related addictive disorders, where mortality rates have been shown to be highly elevated (Laramée et al., 2015; Singleton, Degenhardt, Hall, \& Zabransky, 2009; Sordo et al., 2017; Whiteford et al., 2013), very little has been published about the overall mortality in patients diagnosed with a GD. While GD has been demonstrated to be associated with poor physical health (Black, Shaw, McCormick, \& Allen, 2013; Morasco et al., 2006; Pilver \& Potenza, 2013) and health conditions such as obesity (Black et al., 2013), arteriosclerosis, and heart conditions (Pilver \& Potenza, 2013), limited research has attempted to study the course of patients with GD in regard to overall mortality, including both physical and mental disorders. Furthermore, physical illness may also contribute to mental health-related causes of death; physical illness has been associated with elevated risks of committing suicide even after controlling for mental health-related and socioeconomic risk factors (Crump, Sundquist, Sundquist, \& Winkleby, 2014), and for those with both physical and mental illness, this risk might be even greater (Qin, Hawton, Mortensen, \& Webb, 2014). On the whole, to be best of our knowledge, all-cause mortality to date has not been described in patients with GD, and furthermore, the limited number of studies on GD and completed suicide calls for further research of its extent and risk factors, including its association with other health-related co-factors in the GD population.

\section{Aims}

In this study, for the aforementioned reasons, it was hypothesized that not only suicide rates but also general mortality would be increased for individuals with GD. Since there is no previous knowledge on mortality or the frequency of completed suicide in this population, we aimed to investigate standardized mortality ratios (SMRs) for patients with GD as well as to compare mortality and suicide rates to the general population. Furthermore, we aimed to investigate the effects of specific risk factors previously associated with suicidality and/or suicide attempts on completed suicide among individuals with GD as well as to investigate risk factors in general for mortality.

\section{METHODS}

\section{Material}

This is a nationwide cohort study using national registers containing information on diagnoses and mortality. The study is based on information from the Swedish National Patient Register (NPR) and the Swedish Cause of Death Register (CDR). The NPR is assessed to have a positive predictive value of $85 \%-95 \%$ and covers $99 \%$ of all somatic and mental health hospital discharges and around $80 \%$ of all hospital-based outpatient care (Ludvigsson et al., 2011), the latter percentage probably being lower due to missing data from private caregivers and some mental health outpatient treatment (Forsberg, Rydh, Jacobsson, Nyqvist, \& Heurgren, 2009). Diagnoses were not reported for as many as $56 \%$ of visits in 2005 and $23 \%$ in 2006 for outpatient psychiatry, but missing data have now reached a level of $4 \%$ in outpatient specialist treatment as a whole (The Swedish National Board of Health and Welfare, 2018).

The NPR covers among other information data on primary and secondary diagnoses according to the 10 th revision of International Classification of Diseases (ICD-10) in patients discharged from inpatient care as well as hospitalbased outpatient physician visits. Primary care is not yet included in the register (The Swedish National Board of Health and Welfare, 2018).

\section{Participants and outcome variables}

Between the years of 2005-2016, 2,172 individuals in the NPR had received a diagnosis of GD (pathological gambling, F63.0 according to the ICD-10). In this study, the GD terminology is used, as this is the nomenclature chosen in the upcoming ICD 11 and also is the term in use in the fifth edition of Diagnostic and Statistical Manual of Mental Disorders (American Psychiatric Association, 2013; World Health Organization, 2018). For these individuals, 1,024 hospital admissions and 5,236 medical appointments in the outpatient care were noted, where GD had been either the primary or secondary diagnosis. Mental health and physical comorbidities (Table 1) were described as any occurrence for each ICD-10 diagnostic category at any time during the study period (2005-2006), that is, both prior to and after an individual's first GD diagnosis, in order to describe an extensive picture of disease potentially associated with a risk of death.

Seven hospital admissions were registered where information on personal identification number (PIN) was missing (six men between 27 and 56 years of age and one with a male of unknown age). This was also the case for seven appointments in the specialized outpatient care (men of unknown age). Since PINs were missing, it was impossible to state whether these were 13 different individuals or just a few who had attended the medical system several times. Neither was it possible to follow these individuals in the registers and they were hence excluded. It is likely that these individuals are asylum seekers or non-Swedish residents (The National Board of Health and Welfare). Furthermore, 73 individuals (67 men and 6 women) were excluded, since they were younger than 18 years when included in the study (none of these individuals passed away).

The remaining study population consisting of 2,099 individuals was matched in the CDR and information on causes of death with the subsequent ICD diagnoses were handed to us. The CDR contains information according to the International Form of Medical Certificate of Cause of 
Death. Swedish physicians are obliged to report these data to the National Board of Health and Welfare within 3 weeks from the time of death (Brooke et al., 2017).

All deaths due to homicide are to be reported by the physician performing the forensic autopsy, which is mandatory in these cases, and in $95 \%$ of the deaths due to suicide as well, deaths among known or suspected individuals with alcohol or drug use disorders are also routinely investigated through forensic autopsy (Brooke et al., 2017). In 90\% of forensic autopsies in Sweden, a comprehensive analysis of alcohols, pharmaceuticals, and illicit drugs is to be performed (Brooke et al., 2017). The quality of the Swedish CDR has been estimated through comparison to case reports looking at individuals who passed away in hospital, and $77 \%$ agreement on underlying cause of death was found with higher accuracy among younger patients and 98\% for those between 0 and 44 years of age and $91 \%$ for those between 45 and 64 years of age (Johansson, Björkenstam, \& Westerling, 2009).

We chose not to include diagnoses classified as "undetermined event" (i.e., ICD-10 codes X40-X49 and/or Y10Y34) in the suicide or self-harm categories but rather to keep these apart. This approach has previously been suggested by Björkenstam et al. (2014) who concluded that several background factors separated these cases from clear suicide cases.

\section{Statistical analyses}

Descriptive statistics on overall mental health comorbidity were performed for the whole study population as well as for men and women separately.

SMRs were calculated for overall mortality as well as for suicidal events looking at age categories: $20-74,20-49$, and 50-74 years of age for all individuals as well as for men and women separately. The SMRs were calculated through comparison to the Swedish population. Data on mortality and suicide for the general Swedish population were retrieved from an open access service on Statistics Sweden's official website (Statistics Sweden, 2018). The data provided by Statistics Sweden is readily displayed as number of deaths per 100,000, stratified for sex and age (Statistics Sweden, 2018).

Multivariate Cox regression analyses were performed using SPSS version 24.0 (Armonk, NY, USA) to investigate risk factors for all-cause mortality (all fatalities vs. all other cases) and for suicide mortality (suicide cases vs. all other deceased or surviving cases). The time variables included in the study were the time from inclusion in the cohort (first diagnosis of GD) until censoring (study end) or time of death. In addition to gender and age, comorbidities included as potential predictors of death were defined as any occurrence of the diagnostic categories included, at any time during the full study period (2006-2016). Given the relatively low absolute number of deaths, the number of potential predictors was kept low; in addition to gender and age (age at the start of the observation period), the three markedly most common diagnostic categories of mental health disorders were included; depression (F32-F33), anXiety disorders (F4), and substance-use disorders (F1). For physical disease, a number of diagnostic categories were roughly equally common, and here, the categories corresponding to the most common physical causes of death in the data set were chosen for inclusion as possible predictors of mortality, that is, any treatment episode for these disorders (malignant disease including diseases of the blood and the immune system, ICD-codes $\mathrm{C}$ and $\mathrm{D}$, and cardiovascular disease, code I). In the analysis of prediction of suicide, as the absolute number of cases with this outcome were lower, physical disorders were analyzed together and mental health disorders together and thereafter significant predictors from each analysis were entered together, controlling for gender and age in each analysis.

\section{Ethics}

The study procedures were carried out in accordance with the Declaration of Helsinki, although due to the study design consent was not obtained. The study was approved by the regional ethics committee of Lund, Sweden (file number: 2016/1104).

\section{RESULTS}

A total of 2,099 individuals were included, 18-83 years old at first GD diagnosis (mean: 36.5 years old, $S D: 11.9)$ and a majority were men (77\%), individuals were followed for an average 4.7 years. In the inpatient care setting, $29 \%$ of the individuals had GD as a main diagnosis at some point, whereas $66 \%$ in the outpatient setting had GD as a main diagnosis in the outpatient setting. On the whole, 55\% had GD as main diagnosis at some point in either inpatient or outpatient care.

The most common categories of mental health comorbidity during the whole study period were depression (51\%), anxiety disorders (60\%), and substance-use disorders (41\%). Nineteen percent of subjects received a suicide attempt diagnosis at some time during the full study period (for full results on mental health comorbidity, see Table 1).

During this period, 67 individuals passed away (52 men and 15 women), among whom 21 deaths (18 men, three women) were due to suicides. Median age at death was 51 years (interquartile range: $39-62$ years), and the median age at suicide death was 32.5 years (interquartile range: $41-49.5$ years). The leading causes of death were suicide (31\%) followed by neoplasms $(16 \%)$ and diseases of the circulatory system $(12 \%)$. The entire list can be found in Table 2 .

The SMR results for overall mortality indicated a 1.8-fold increase in mortality for individuals 20-74 years old with GD compared to the general population, for men 1.5 times and for women 2.1 times. In the younger age categories, 20-49 years of age, mortality was 6.2 times greater than that of the general population, 4.6 times for men and 10.5 times for women. There was no significant increase in the age category 50-74 years of age (Table 3 ).

SMR for suicide indicated a 15.1 times increase for men and women 20-74 years of age and in the younger and older age categories 19.3 and 9.6 times, respectively. For men alone, the overall increase was 12.1 times (14.3 times for those 20-49 years of age and 9.5 for those 50-74 years of age). For women, no significant results were obtained (Table 4). 
Table 1. Comorbidity in the study population $(N=2,099)$ occurring at any time during the study period (2005-2016) in inpatient or outpatient specialist care

\begin{tabular}{|c|c|c|c|}
\hline ICD-10 code & Disease & $n$ & $\%$ \\
\hline $\mathrm{AB}$ & Certain infectious and parasitic diseases & 447 & 21 \\
\hline $\mathrm{CD}$ & Neoplasms, diseases of the blood, and diseases involving the immune mechanism & 385 & 18 \\
\hline $\mathrm{E}$ & Endocrine, nutritional, and metabolic diseases & 376 & 18 \\
\hline G & Diseases of the nervous system & 414 & 20 \\
\hline $\mathrm{H}$ & Diseases of the eye and the ear & 493 & 23 \\
\hline I & Diseases of the circulatory system & 397 & 19 \\
\hline $\mathrm{J}$ & Diseases of the respiratory system & 516 & 25 \\
\hline $\mathrm{K}$ & Diseases of the digestive system & 656 & 31 \\
\hline $\mathrm{L}$ & Diseases of the skin & 500 & 24 \\
\hline M & Diseases of the musculoskeletal system & 848 & 40 \\
\hline $\mathrm{N}$ & Diseases of the genitourinary system & 604 & 29 \\
\hline $\mathrm{O}$ & Pregnancy, childbirth, and the puerperium & 122 & 6 \\
\hline Q & Congenital malformations & 56 & 3 \\
\hline $\mathrm{R}$ & Symptoms, signs, and findings, not elsewhere classified & 1,225 & 58 \\
\hline ST & Injury, poisoning, and other consequences of external causes & 1,365 & 65 \\
\hline V0-X59 & Accidents (excluding accidental poisoning) & 1,085 & 52 \\
\hline $\mathrm{X} 40-\mathrm{X} 49$ & Accidental poisoning & 68 & 3 \\
\hline X60-X84 & Intentional self-harm & 406 & 19 \\
\hline X85-Y09, Y35-Y36 & Assault, legal intervention, or operation of war & 226 & 11 \\
\hline Y10-Y34 & Events of undetermined intent & 96 & 5 \\
\hline Y40-Y98 & Other external causes & 319 & 15 \\
\hline F00-F09 & Organic, including symptomatic and mental disorders & 48 & 2 \\
\hline F10-F19 & Mental and behavioral disorders due to psychoactive substance use (substance-use disorders) & 859 & 41 \\
\hline F10 & Mental and behavioral disorders due to use of alcohol & 618 & 29 \\
\hline F11-F19 & Mental and behavioral disorders due to use of drugs & 534 & 25 \\
\hline F20-F29 & Schizophrenia, schizotypal, and delusional disorders & 196 & 9 \\
\hline F32-F33 & Depressive disorders & 1,073 & 51 \\
\hline F30-F31 & Bipolar disorders & 250 & 12 \\
\hline F34-F39 & Other mood disorders & 123 & 6 \\
\hline F40-F48 & Neurotic, stress-related, and somatoform disorders (anxiety disorders) & 1,252 & 60 \\
\hline F50 & Eating disorders & 57 & 3 \\
\hline F52 & Sexual disorders & 28 & 1 \\
\hline F60-F62 & Personality disorders & 408 & 19 \\
\hline F63 & Impulse control disorders (excluding F63.0) & 99 & 5 \\
\hline F64-F69 & Other disorders of personality & 41 & 2 \\
\hline F70-F79 & Mental retardation & 37 & 2 \\
\hline F80-F89 & Pervasive and specific developmental disorders & 129 & 6 \\
\hline F90-F98 & Behavioral and emotional disorders with onset usually occurring in childhood and adolescence & 360 & 17 \\
\hline F99 & Unspecified disorder & 72 & 3 \\
\hline
\end{tabular}

Note. Diagnostic categories derived from the International Classification of Disease 10th revision (ICD-10).

Table 2. Underlying cause of death $(N=67)$ categorized according to the International Classification of Disease 10th revision (ICD-10)

\begin{tabular}{|c|c|c|c|}
\hline ICD code & Diagnostic category & $n$ & $\%$ \\
\hline A00-B99 & Certain infectious and parasitic diseases & 2 & 3 \\
\hline $\mathrm{C} 00-\mathrm{D} 48$ & Neoplasms & 11 & 16 \\
\hline F00-F99 & Mental and behavioral disorders & 2 & 3 \\
\hline G00-G99 & Diseases of the nervous system & 2 & 3 \\
\hline I00-I99 & Diseases of the circulatory system & 8 & 12 \\
\hline J00-J99 & Diseases of the respiratory system & 4 & 6 \\
\hline N00-N99 & Diseases of the genitourinary system & 1 & 1 \\
\hline R90-R99 & Unknown cause of death & 4 & 6 \\
\hline W00-W99 & Falls & 1 & 1 \\
\hline $\mathrm{X} 40-49$ & Accidental poisoning by and exposure to noxious substances & 4 & 6 \\
\hline X60-X84 & Intentional self-harm & 21 & 31 \\
\hline $\mathrm{X} 85-\mathrm{Y} 09$ & Assault & 1 & 1 \\
\hline Y10-Y34 & Event of undetermined intent & 6 & 9 \\
\hline $\mathrm{A}-\mathrm{Y}$ & All deaths & 67 & 100 \\
\hline
\end{tabular}


Table 3. SMRs stratified for different sex and age categories presented with a 95\% CI

\begin{tabular}{|c|c|c|c|c|c|c|}
\hline \multirow[b]{2}{*}{ Gender } & \multicolumn{2}{|c|}{ 20-74 years old } & \multicolumn{2}{|c|}{ 20-49 years old } & \multicolumn{2}{|c|}{ 50-74 years old } \\
\hline & SMR & $95 \% \mathrm{CI}$ & SMR & $95 \% \mathrm{CI}$ & SMR & $95 \% \mathrm{CI}$ \\
\hline Men and women & $1.8^{*}$ & {$[1.4-2.2]$} & $6.2^{*}$ & {$[4.1-8.4]$} & 1.3 & [0.9-1.8] \\
\hline Men & $1.5^{*}$ & [1.1-1.9] & $4.6^{*}$ & {$[2.7-6.5]$} & 1.2 & {$[0.8-1.7]$} \\
\hline Women & $2.1^{*}$ & {$[1.0-3.3]$} & $10.5^{*}$ & [2.7-18.2] & 1.3 & [0.3-2.3] \\
\hline
\end{tabular}

Note. Swedish individuals with gambling disorder compared to the Swedish general population in 2016. CI: confidence interval; SMR: standardized mortality ratio.

*Significant result.

Table 4. SMRs for suicide stratified for different sex and age categories presented with a $95 \% \mathrm{CI}$

\begin{tabular}{|c|c|c|c|c|c|c|}
\hline \multirow[b]{2}{*}{ Gender } & \multicolumn{2}{|c|}{ 20-74 years old } & \multicolumn{2}{|c|}{$20-49$ years old } & \multicolumn{2}{|c|}{ 50-74 years old } \\
\hline & SMR & $95 \% \mathrm{CI}$ & SMR & $95 \% \mathrm{CI}$ & SMR & $95 \% \mathrm{CI}$ \\
\hline Men and women & $15.1^{*}$ & [8.7 to 21.6$]$ & $19.3^{*}$ & [9.8 to 28.7$]$ & $9.6^{*}$ & {$[1.2-18.0]$} \\
\hline Men & $12.1^{*}$ & [6.5 to 17.7$]$ & $14.3^{*}$ & [6.5 to 22.0$]$ & $9.5^{*}$ & {$[1.2-17.8]$} \\
\hline Women & 16.1 & [-2.1 to 34.3$]$ & 30.1 & {$[-4.0$ to 64.2$]$} & & \\
\hline
\end{tabular}

Note. Swedish individuals with gambling disorder compared to the Swedish general population in 2016. CI: confidence interval; SMR: standardized mortality ratio.

*Significant result. **No documented suicides in this category.

Table 5. Multivariate Cox regression analysis of predictors of all-cause mortality $(N=2,099)$

\begin{tabular}{lccc}
\hline Factor & HR & $95 \% \mathrm{CI}$ & $p$ \\
\hline Female gender & 0.82 & {$[0.46-1.48]$} & .51 \\
Age at first gambling disorder & 1.04 & {$[1.02-1.07]$} & $<.001^{*}$ \\
$\quad$ diagnosis (years) & & & \\
Substance-use disorder & 1.18 & {$[0.72-1.94]$} & .51 \\
Depression & 1.01 & {$[0.61-1.70]$} & .96 \\
Anxiety & 0.84 & {$[0.50-1.40]$} & .50 \\
Malignant disease & 1.62 & {$[0.96-2.73]$} & .07 \\
Cardiovascular disease & 2.32 & {$[1.33-4.02]$} & $<.01^{*}$ \\
\hline
\end{tabular}

Note. This table shows hazard ratios (HR) with a $95 \%$ confidence interval $(95 \% \mathrm{CI})$ and level of significance $(p)$.

*Significant result.

In the multivariate Cox regression analysis, all-cause mortality was predicted by older age and by having a cardiovascular diagnosis at any time during the study period (Table 5). For suicide mortality, none of the physical disease variables (malignant disease and cardiovascular disease) were significant predictors (Table 6). Among mental health variables, while controlling for gender and age, suicide deaths were significantly predicted by a depression diagnosis anytime during the study period (Table 7).

\section{DISCUSSION}

To our knowledge, this is the first longitudinal, nationwide study on suicide and mortality rates among individuals with GD, and it is one of the few studies focusing on completed suicide in GD. Suicide was indeed the leading cause of death in this population $(n=21,31 \%)$ and the present findings indicate elevated risks of both suicide and premature death
Table 6. Multivariate Cox regression analysis of potential physical diseases as predictors of suicide death, controlled for gender and age $(N=2,099)$

\begin{tabular}{lccc}
\hline Factor & HR & $95 \%$ CI & $p$ \\
\hline Female gender & 0.63 & {$[0.18-2.17]$} & .47 \\
Age at first gambling disorder & 1.02 & {$[0.99-1.06]$} & .21 \\
$\quad$ diagnosis (years) & & & \\
Malignant disease & 0.38 & {$[0.09-1.69]$} & .20 \\
Cardiovascular disease & 1.02 & {$[0.34-3.03]$} & .98 \\
\hline
\end{tabular}

Note. This table shows hazard ratios (HR) with a $95 \%$ confidence interval $(95 \% \mathrm{CI})$ and level of significance $(p)$.

Table 7. Multivariate Cox regression analysis of potential psychiatric predictors of suicide death, controlled for gender and age $(N=2,099)$

\begin{tabular}{lccc}
\hline Factor & HR & $95 \%$ CI & $p$ \\
\hline Female gender & 0.49 & {$[0.14-1.67]$} & .25 \\
Age at first GD diagnosis (years) & 1.02 & {$[0.98-1.05]$} & .37 \\
Substance-use disorder & 1.10 & {$[0.46-2.63]$} & .83 \\
Depression & 5.45 & {$[1.57-18.93]$} & $<.01^{*}$ \\
Anxiety & 0.87 & {$[0.34-2.22]$} & .77 \\
\hline
\end{tabular}

Note. This table shows hazard ratios (HR) with a $95 \%$ confidence interval $(95 \% \mathrm{CI})$ and level of significance $(p)$.

*Significant result.

in individuals with GD. The increase in mortality was especially pronounced among younger individuals, that is, below 49 years of age. This is notable since GD is more common in the young (mean age: 36.5 years). The second and third leading causes of mortality were "neoplasms" and "diseases of the circulatory system." 
SMRs on overall mortality and suicide were elevated in this study as expected. To our knowledge, there have not been any previous attempts to estimate SMRs for individuals with GD and thus we will attempt to compare these to literature on other mental and addictive disorders. Concerning general SMRs, these were at similar to lower levels when comparing to literature on different populations with mental disorders. A meta-analysis on bipolar disorder indicated SMR levels similar to this study (Hayes, Miles, Walters, King, \& Osborn, 2015). In a population of individuals with amphetamine use in the criminal justice system in the setting studied here, the SMR for the younger age category (20-49 years of age) was also similar (Ericsson, Brådvik, \& Håkansson, 2014); although when looking at the entire age span (20-74 years of age), the SMR in this study was slightly lower (Ericsson et al., 2014). Similarly, the present SMR figures were lower than in a cohort of injecting amphetamine users ( $\AA$ hman, Jerkeman, Blomé, Björkman, \& Håkansson, 2018), and in patients with heroin dependence (Pan et al., 2014). When comparing to a study on individuals with general mental disorders, SMR levels in this study were also slightly lower (Charrel et al., 2015), and markedly lower when compared to a population of individuals hospitalized for substance-use disorders (Fugelstad, Annell, \& Ågren, 2014). However, the much higher mortality rate in the latter study might be explained by the fact that many of the participants in this study were instead included from outpatient care.

Regarding SMRs for suicide, the results were similar to those described for other populations of individuals with mental disorders. The aforementioned studies on bipolar disorder, other mental disorders, and individuals hospitalized for substance-use disorders, as well as a large study on recent-onset mental illness in the Scandinavian countries indicated SMRs for suicide at comparable levels (Charrel et al., 2015; Fugelstad et al., 2014; Hayes et al., 2015; Nordentoft et al., 2013). On the whole, mortality and completed suicide are elevated when compared to the general population, and this is markedly more pronounced for suicide mortality than for all-cause mortality, and the risk increase is roughly in line with the increased mortality and suicide rates observed in other populations with mental disorders.

Older age and diseases of the circulatory system predicted general mortality. This finding, together with the knowledge that GD is associated with increased prevalence of arteriosclerosis and heart conditions (Pilver \& Potenza, 2013), calls for further research on the association between GD and diseases of the circulatory system. Screening for cardiovascular disease might be of future interest among individuals with GD. None of the mental disorders investigated increased the general mortality. However, having a diagnosis of depression increased the risk of completed suicide. Suffering from depression was indeed the only risk factor for committing suicide in this study. The link between depression and suicide deaths, although assessed in this cohort of subjects with GD, is far from surprising; depression is a well-known predictor of suicide (Ferrari et al., 2013). Given the low absolute number of suicides in this study, more research is needed in larger data materials, in order to describe the potential role of additional mental health disorders.

An increase in mental health comorbidity among women was observed in a descriptive study on the present register data (Håkansson, Karlsson, \& Widinghoff, 2018), and women were more likely than men to have affective disorders (ICD-10 code F3), neurotic, stress-related and somatoform disorders, behavioral syndromes associated with physiological disturbances and physical factors, and disorders of adult personality and behavior (ICD-10 codes F4, F5, and F6, respectively) (Håkansson et al., 2018). In addition, in the literature, several reports have concluded that female sex may be a risk factor of suicidality and/or suicide attempts in patients with GD (Bischof et al., 2015; Husky et al., 2015; Komoto, 2014). In some contrast to the overall risk increase for suicide in men in the general population (Hawton \& van Heeringen, 2009), importantly, in this study, male gender was not a risk factor as expected from the general population. This further draws the attention to female gender as a relative risk factor for suicide in GD patients, compared to other mental health disorders. Future studies on women with GD and completed suicide are required; also, as the proportion of women diagnosed with GD in this material was rather small, this may require further investigation in larger data materials. It has been predicted that the proportion of women with problem gambling will increase slightly in the present setting (Abbott, Romild, \& Volberg, 2018), further enhancing the need to focus on gender-specific risk factors for suicide.

Regarding the diagnostics of suicide, we chose to include only those with a diagnosis of "intentional selfharm." As previously mentioned, this decision was taken due to differences on risk factors for death due to "intentional self-harm" and "events of undetermined intent" (Björkenstam et al., 2014). In addition, in drug use disorder research, different risk factors have been associated with the two diagnostic groups (Olsson, Brådvik, Öjehagen, \& Håkansson, 2016). However, it has been reported that some deaths classified as "events of undetermined intent" may in fact represent actual suicides, and in an effort to investigate diagnoses in Scandinavian death certificates, it was estimated that as many as $21 \%$ of deaths due to "event of undetermined intent" should be considered "intentional self-harm" (Tøllefsen et al., 2015). Rates of suicide have although been estimated to remain roughly the same in the Scandinavian countries when investigating these two diagnostic categories with some deaths being incorrectly classified as deaths due to "intentional self-harm" and similarly some deaths classified as "events of undetermined events" should have been classified as "intentional self-harm" (Tøllefsen et al., 2015). In this study, six individuals passed away due to "event of undetermined intent," such that some of these individuals potentially may indeed have represented "intentional self-harm."

Future research on suicide among individuals with GD would preferably combine mental health comorbidity, socioeconomic factors such as bankruptcy rates as well as family history of GD and other addictions. As for socioeconomic factors, a study from Hong Kong on 
completed suicide indicated a $19 \%$ incidence of prior gambling activities among which $42 \%$ had been put into dept due to gambling (Wong et al., 2010). Financial problems have also been associated with attempted suicide (Komoto, 2014; Wong et al., 2010), as have bankruptcy (Komoto, 2014), financial debts (Ronzitti et al., 2017), unemployment (Komoto, 2014), addiction among family members (Komoto, 2014), being a teenager (Newman \& Thompson, 2007), and having lower education level (Newman \& Thompson, 2007). In addition, research on the genetic aspects of suicide among individuals with GD might be motivated in the future. It has been suggested that $43 \%$ of the propensity to engage in gambling is attributable to genetics (Slutske et al., 2009), and that the genetic impact is even greater for women (Slutske, Ellingson, Richmond-Rakerd, Zhu, \& Martin, 2013). Thus, several factors need to be taken into account, apart from only diagnostic variables and basic demographic data. However, this study provides diagnostic data in a relatively large data set of patients. Future longitudinal follow-up in GD may merit from a more in-depth combination of diagnostic and sociodemographic, including financial data.

\section{Limitations}

Treatment uptake for GD is increasing in the Swedish health care system, but there is still a gap between the number of gambling patients in the health care system and the number of individuals with a likely GD in the population (Håkansson et al., 2018). Furthermore, since primary care is not included in the national registers, there are some individuals with GD who could not be investigated in this study. It is therefore likely that results may be skewed toward a population of individuals with more severe forms of GD. It is likely that this once again implies that this study sample might contain patients with higher mental health comorbidity, as well as individuals with more severe forms of GD, since these individuals are more likely to receive specialized psychiatry care.

Furthermore, since this study investigates completed suicide rather than attempts or suicidal ideation, the number of analyses possible to run were limited due to the relatively low number of events. That being said, research investigating completed suicide plays a very important part of understanding the relationship between GD and suicide, and larger studies are needed in the area. Also, another limitation is the lack of a control group; thus, mortality and risk factors are assessed within the group of patients with GD, rather than in comparison to non-GD patients.

Furthermore, this study did not assess those younger than 18 years of age due to the risk of confusion in terminology; the Swedish word for gambling is the same as that for gaming, which, however, is not represented by a diagnostic entity in the ICD-10 system used here. We feared that it would be problematic to assume that the greater majority of those below 18 years of age did have a GD. As awareness and knowledge of GD is likely to increase over time, future research might provide better means of researching this younger population in a similar manner, providing important knowledge on younger individuals with GD.

\section{Strengths}

This is a nationwide study in which a large number of individuals diagnosed with GD have been included. The extensive information in the national registers on causes of death as well as mental disease and other diseases allows for unique opportunities to investigate actual suicide and mortality rates among individuals with GD compared to the general population as well as investigating risk factors for premature death and suicide. This study investigates completed suicide and also utilizes a longitudinal design, which to our knowledge has not previously been done with regard to suicide and GD. Nor have previous calculations on SMRs, to our knowledge, been undertaken.

\section{CONCLUSIONS}

Mortality and particularly suicide rates are greatly elevated among individuals with a diagnosis of GD. Regarding overall mortality, standardized mortality rates were highest for those younger than 49 years of age. Efforts to assess and prevent the risk of suicide for individuals with GD as main or secondary diagnosis are important. Neither of the most common mental health disorders or substance-use disorder diagnoses predicted overall mortality (which was predicted by cardiovascular disease and older age), but this calls for further study and prevention of health problems, including physical disease, in GD patients. Depression was a significant predictor of suicide death, and this calls for enhanced focus on the mental health comorbidity in GD.

Funding sources: No financial support was received specifically for this study. AH holds at position as professor at Lund University financed in collaboration between Lund University and the Swedish gambling operator monopoly, Svenska spel AB, as a part of the latter part's responsibility for gambling and research policy, but this funding is not aimed for any projects specifically, and the funding body has no influence on the research ideas, research designs or interpretations, and publications of findings.

Authors' contribution: AK: contributed in performing the statistical analysis and interpretation of data as well as literature review and the main writing of the paper. $\mathrm{AH}$ : overall responsible of the research idea and the project lead; responsible for ethics permission, study design, and application for register data access; had full access to the data; and interpreted the results, study supervision, and co-writing of the paper.

Conflict of interest: The authors declare no conflict of interest with relevance to this study. 


\section{REFERENCES}

Abbott, M., Romild, U., \& Volberg, R. (2018). The prevalence, incidence, and gender and age-specific incidence of problem gambling: Results of the Swedish longitudinal gambling study (Swelogs). Addiction, 113(4), 699-707. doi:10.1111/add.14083

Åhman, A., Jerkeman, A., Blomé, M. A., Björkman, P., \& Håkansson, A. (2018). Mortality and causes of death among people who inject amphetamine: A long-term follow-up cohort study from a needle exchange program in Sweden. Drug and Alcohol Dependence, 188, 274-280. doi:10.1016/j.drugalcdep. 2018.03.053

American Psychiatric Association. (2013). Diagnostic and statistical manual of psychiatric disorders. Arlington, VA: American Psychiatric Association.

Bischof, A., Meyer, C., Bischof, G., John, U., Wurst, F. M., Thon, N., Lucht, M., Grabe, H. J., \& Rumpf, H. J. (2015). Suicidal events among pathological gamblers: The role of comorbidity of axis I and axis II disorders. Psychiatry Research, 225(3), 413-419. doi:10.1016/j.psychres.2014.11.074

Björkenstam, C., Johansson, L. A., Nordstrom, P., Thiblin, I., Fugelstad, A., Hallqvist, J., \& Ljung, R. (2014). Suicide or undetermined intent? A register-based study of signs of misclassification. Population Health Metrics, 12(1), 11. doi:10. 1186/1478-7954-12-11

Black, D. W., Shaw, M., McCormick, B., \& Allen, J. (2013). Pathological gambling: Relationship to obesity, self-reported chronic medical conditions, poor lifestyle choices, and impaired quality of life. Comprehensive Psychiatry, 54(2), 97-104. doi:10.1016/j.comppsych.2012.07.001

Blaszczynski, A., \& Farrell, E. (1998). A case series of 44 completed gambling-related suicides. Journal of Gambling Studies, 14(2), 93-109. doi:10.1023/A:1023016224147

Braun, B., Ludwig, M., Sleczka, P., Buhringer, G., \& Kraus, L. (2014). Gamblers seeking treatment: Who does and who doesn't? Journal of Behavioral Addictions, 3(3), 189-198. doi:10.1556/JBA.3.2014.3.7

Brooke, H. L., Talbäck, M., Hörnblad, J., Johansson, L. A., Ludvigsson, J. F., Druid, H., Feychting, M., \& Ljung, R. (2017). The Swedish cause of death register. European Journal of Epidemiology, 32(9), 765-773. doi:10.1007/s10654-017-0316-1

Calado, F., \& Griffiths, M. D. (2016). Problem gambling worldwide: An update and systematic review of empirical research (20002015). Journal of Behavioral Addictions, 5(4), 592-613. doi:10.1556/2006.5.2016.073

Charrel, C. L., Plancke, L., Genin, M., Defromont, L., Ducrocq, F., Vaiva, G., \& Danel, T. (2015). Mortality of people suffering from mental illness: A study of a cohort of patients hospitalised in psychiatry in the north of France. Social Psychiatry and Psychiatric Epidemiology, 50(2), 269-277. doi:10.1007/ s00127-014-0913-1

Crump, C., Sundquist, K., Sundquist, J., \& Winkleby, M. A. (2014). Sociodemographic, psychiatric and somatic risk factors for suicide: A Swedish national cohort study. Psychological Medicine, 44(2), 279-289. doi:10.1017/s0033291713000810

Ericsson, E., Brådvik, K., \& Håkansson, A. (2014). Mortality, causes of death and risk factors for death among primary amphetamine users in the Swedish criminal justice system. Substance Use and Misuse, 49, 262-269. doi:10.3109/ 10826084.2013.825921
Ferrari, A. J., Charlson, F. J., Norman, R. E., Patten, S. B., Freedman, G., Murray, C. J., Vos, T., \& Whiteford, H. A. (2013). Burden of depressive disorders by country, sex, age, and year: Findings from the global burden of disease study 2010. PLoS Medicine, 10(11), e1001547. doi:10.1371/journal.pmed.1001547

Forsberg, L., Rydh, H., Jacobsson, A., Nyqvist, K., \& Heurgren, M. (2009). Kvalitet och innehåll i patientregistret. Utskrivningar från slutenvården 1964-2007 och besök $i$ specialiserad öppenvård (exklusive primärvårdsbesök) 1997-2007 [Quality and contents of the patient register. Discharges from in-patient care 1964-2007 and visits to specialized outpatient care (excluding primary care visits) 1997-2007] (Report: 2009-125-15). Stockholm, Sweden: The National Board of Health and Welfare.

Fugelstad, A., Annell, A., \& Ågren, G. (2014). Long-term mortality and causes of death among hospitalized Swedish drug users. Scandinavian Journal of Public Health, 42(4), 364-369. doi:10.1177/1403494814525006

Håkansson, A., Karlsson, A., \& Widinghoff, C. (2018). Primary and secondary pathological gambling diagnoses and psychiatric comorbidity in the health care system - A nationwide register study. Front Psychiatry, 9, 426. doi:10.3389/fpsyt. 2018.00426

Hansen, M., \& Rossow, I. (2008). Gambling and suicidal behaviour. Tidsskr Nor Laegeforen, 128(2), 174-176.

Hawton, K., \& van Heeringen, K. (2009). Suicide. Lancet, 373(9672), 1372-1381. doi:10.1016/S0140-6736(09)60372-X

Hayes, J. F., Miles, J., Walters, K., King, M., \& Osborn, D. P. (2015). A systematic review and meta-analysis of premature mortality in bipolar affective disorder. Acta Psychiatrica Scandinavica, 131, 417-425. doi:10.1111/acps. 12408

Husky, M. M., Michel, G., Richard, J. B., Guignard, R., \& Beck, F. (2015). Gender differences in the associations of gambling activities and suicidal behaviors with problem gambling in a nationally representative French sample. Addictive Behaviors, 45, 45-50. doi:10.1016/j.addbeh.2015.01.011

Johansson, L. A., Björkenstam, C., \& Westerling, R. (2009). Unexplained differences between hospital and mortality data indicated mistakes in death certification: An investigation of 1, 094 deaths in Sweden during 1995. Journal of Clinical Epidemiology, 62(11), 1202-1209. doi:10.1016/j.jclinepi.2009. 01.010

Kausch, O. (2003). Suicide attempts among veterans seeking treatment for pathological gambling. The Journal of Clinical Psychiatry, 64(9), 1031-1038. doi:10.4088/JCP.v64n0908

Kessler, R. C., Hwang, I., LaBrie, R., Petukhova, M., Sampson, N. A., Winters, K. C., \& Shaffer, H. J. (2008). DSM-IV pathological gambling in the National Comorbidity Survey Replication. Psychological Medicine, 38(9), 1351-1360. doi:10.1017/S0033291708002900

Komoto, Y. (2014). Factors associated with suicide and bankruptcy in Japanese pathological gamblers. International Journal of Mental Health Addiction, 12(5), 600-606. doi:10.1007/ s11469-014-9492-3

Laramée, P., Leonard, S., Buchanan-Hughes, A., Warnakula, S., Daeppen, J. B., \& Rehm, J. (2015). Risk of all-cause mortality in alcohol-dependent individuals: A systematic literature review and meta-analysis. EBioMedicine, 2(10), 1394-1404. doi:10.1016/j.ebiom.2015.08.040

Ledgerwood, D. M., Steinberg, M. A., Wu, R., \& Potenza, M. N. (2005). Self-reported gambling-related suicidality among 
gambling helpline callers. Psychology of Addictive Behaviors, 19(2), 175-183. doi:10.1037/0893-164X.19.2.175

Ludvigsson, J. F., Andersson, E., Ekbom, A., Feychting, M., Kim, J. L., Reuterwall, C., Heurgren, M., \& Olausson, P. O. (2011). External review and validation of the Swedish National Inpatient Register. BMC Public Health, 11, 450. doi:10.1186/14712458-11-450

Moghaddam, J. F., Yoon, G., Dickerson, D. L., Kim, S. W., \& Westermeyer, J. (2015). Suicidal ideation and suicide attempts in five groups with different severities of gambling: Findings from the National Epidemiologic Survey on Alcohol and Related Conditions. The American Journal on Addictions, 24(4), 292-298. doi:10.1111/ajad.12197

Morasco, B. J., Pietrzak, R. H., Blanco, C., Grant, B. F., Hasin, D., \& Petry, N.M. (2006). Health problems and medical utilization associated with gambling disorders: Results from the National Epidemiologic Survey on Alcohol and Related Conditions. Psychosomatic Medicine, 68(6), 976-984. doi:10.1097/01. psy.0000238466.76172.cd

Newman, S. C., \& Thompson, A. H. (2007). The association between pathological gambling and attempted suicide: Findings from a national survey in Canada. Canadian Journal of Psychiatry, 52(9), 605-612. doi:10.1177/070674370705200909

Nordentoft, M., Wahlbeck, K., Hallgren, J., Westman, J., Osby, U., Alinaghizadeh, H., Gissler, M., \& Laursen, T. M. (2013). Excess mortality, causes of death and life expectancy in 270,770 patients with recent onset of mental disorders in Denmark, Finland and Sweden. PLoS One, 8(1), e55176. doi:10.1371/journal.pone.0055176

Olsson, M. O., Brådvik, L., Öjehagen, A., \& Håkansson, A. (2016). Risk factors for unnatural death: Fatal accidental intoxication, undetermined intent and suicide: Register follow-up in a criminal justice population with substance use problems. Drug and Alcohol Dependence, 162, 176-181. doi:10.1016/j.drugalcdep.2016.03.009

Pan, C. H., Jhong, J. R., Tsai, S. Y., Lin, S. K., Chen, C. C., \& Kuo, C. J. (2014). Excessive suicide mortality and risk factors for suicide among patients with heroin dependence. Drug and Alcohol Dependence, 145, 224-230. doi:10.1016/j.drugalcdep. 2014.10.021

Petry, N. M., Stinson, F. S., \& Grant, B. F. (2005). Comorbidity of DSM-IV pathological gambling and other psychiatric disorders: Results from the National Epidemiologic Survey on Alcohol and Related Conditions. The Journal of Clinical Psychiatry, 66(5), 564-574. doi:10.4088/JCP.v66n0504

Pilver, C. E., \& Potenza, M. N. (2013). Increased incidence of cardiovascular conditions among older adults with pathological gambling features in a prospective study. Journal of Addiction Medicine, 7(6), 387-393. doi:10.1097/ADM. 0b013e31829e9b36

Qin, P., Hawton, K., Mortensen, P. B., \& Webb, R. (2014). Combined effects of physical illness and comorbid psychiatric disorder on risk of suicide in a national population study. The British Journal of Psychiatry, 204(6), 430-435. doi:10.1192/ bjp.bp.113.128785

Retz, W., Ringling, J., Retz-Junginger, P., Vogelgesang, M., \& Rosler, M. (2016). Association of attention-deficit/ hyperactivity disorder with gambling disorder. Journal of Neural Transmission (Vienna), 123(8), 1013-1019. doi:10.1007/s00702016-1566-x
Ronzitti, S., Soldini, E., Smith, N., Potenza, M. N., Clerici, M., \& Bowden-Jones, H. (2017). Current suicidal ideation in treatment-seeking individuals in the United Kingdom with gambling problems. Addictive Behaviors, 74, 33-40. doi:10.1016/j.addbeh.2017.05.032

Singleton, J., Degenhardt, L., Hall, W., \& Zabransky, T. (2009). Mortality among amphetamine users: A systematic review of cohort studies. Drug and Alcohol Dependence, 105(1-2), 1-8. doi:10.1016/j.drugalcdep.2009.05.028

Slutske, W. S., Ellingson, J. M., Richmond-Rakerd, L. S., Zhu, G., \& Martin, N. G. (2013). TShared genetic vulnerability for disordered gambling and alcohol use disorder in men and women: Evidence from a national community-based Australian Twin Study. Twin Research and Human Genetics, 16(2), 525 534. doi:10.1017/thg.2013.11

Slutske, W. S., Meier, M. H., Zhu, G., Statham, D. J., Blaszczynski, A., \& Martin, N. G. (2009). The Australian Twin Study of Gambling (OZ-GAM): Rationale, sample description, predictors of participation, and a first look at sources of individual differences in gambling involvement. Twin Research and Human Genetics, 12, 63-78. doi:10.1375/twin.12.1.63

Sordo, L., Barrio, G., Bravo, M. J., Indave, B. I., Degenhardt, L., Wiessing, L., Ferri, M., \& Pastor-Barriuso, R. (2017). Mortality risk during and after opioid substitution treatment: Systematic review and meta-analysis of cohort studies. BMJ, 357, j1550. doi:10.1136/bmj.j1550

Statistics Sweden. (2018). Finding statistics. Retrieved August 20, 2018, from http://www.statistikdatabasen.scb.se/pxweb/en/ssd/ START_HS_HS0301/DodaOrsak/?rxid=d560892d-3a5c4830-82d9-b4b6c4f1985b

Suurvali, H., Hodgins, D., Toneatto, T., \& Cunningham, J. (2008). Treatment seeking among Ontario problem gamblers: Results of a population survey. Psychiatric Services, 59, 1343-1346. doi:10.1176/appi.ps.59.11.1343

The Swedish National Board of Health and Welfare. (2018). Patientregistret. Bortfall och kvalitet [The patient register. Attrition and quality]. Stockholm, Sweden: The Swedish National Board of Health and Welfare.

Tøllefsen, I. M., Helweg-Larsen, K., Thiblin, I., Hem, E., Kastrup, M. C., Nyberg, U., Rogde, S., Zahl, P. H., Østevold, G., \& Ekeberg, Ø. (2015). Are suicide deaths under-reported? Nationwide re-evaluations of 1800 deaths in Scandinavia. BMJ Open, 5, e009120. doi:10.1136/bmjopen-2015-009120

Tse, S., Tang, J., \& Wong, P. (2014). Fortune or foe: The fatal harm caused by a gambling disorder. Addiction, 109(12), 2135-2135. doi:10.1111/add.12744

Whiteford, H. A., Degenhardt, L., Rehm, J., Baxter, A. J., Ferrari, A. J., Erskine, H. E., Charlson, F. J., \& Norman, R. E. (2013). Global burden of disease attributable to mental and substance use disorders: Findings from the Global Burden of Disease Study 2010. Lancet, 382(9904), 1575-1586. doi:10.1016/ S0140-6736(13)61611-6

Wong, P. W., Cheung, D. Y., Conner, K. R., Conwell, Y., \& Yip, P. S. (2010). Gambling and completed suicide in Hong Kong: A review of coroner court files. Prim Care Companion to the Journal of Clinical Psychiatry, 12(6), e1-e7. doi:10.4088/ PCC.09m00932blu

World Health Organization. (2018). International classification of diseases. Mortality and morbidity statistics (11th rev.). Geneva, Switzerland: World Health Organization. 